Article

\title{
Intestinal Absorption of Triterpenoids and Flavonoids from Glycyrrhizae radix et rhizoma in the Human Caco-2 Monolayer Cell Model
}

\author{
Xiao-Xue Wang ${ }^{1,2}$, Gui-Yan Liu ${ }^{1, *}$, Yan-Fang Yang ${ }^{2}$, Xiu-Wen $\mathrm{Wu}^{2}$, Wei $\mathrm{Xu}^{2}$ \\ and Xiu-Wei Yang ${ }^{2, *}$ \\ 1 School of Life Science and Technology, Beijing Institute of Technology, No. 5, Zhongguancun South Street, \\ Haidian District, Beijing 100081, China; 18813007559@163.com \\ 2 State Key Laboratory of Natural and Biomimetic Drugs, Department of Natural Medicines, \\ School of Pharmaceutical Sciences, Peking University Health Science Center, Peking University, No. 38, \\ Xueyuan Road, Haidian District, Beijing 100191, China; yangyanfang@bjmu.edu.cn (Y.-F.Y.); \\ wuxiuwen0725@126.com (X.-W.W.); high-xu@163.com (W.X.) \\ * Correspondence: gyliu@bit.edu.cn (G.-Y.L.); xwyang@bjmu.edu.cn (X.-W.Y.); \\ Tel.: +86-10-6891-8203 (G.-Y.L.); +86-10-8280-1569 (X.-W.Y.); Fax: +86-10-8280-2724 (X.-W.Y.)
}

Received: 12 September 2017; Accepted: 27 September 2017; Published: 29 September 2017

\begin{abstract}
Glycyrrhizae radix et rhizoma has been used as a traditional Chinese medicine for the treatment of various diseases. Triterpenoids and flavonoids from the plant have many beneficial effects and their chemical structures are modified in the gastrointestinal tract after oral administration. However, absorption of these triterpenoids and flavonoids still needs to be defined. Here, the uptake and transepithelial transport of the selected major triterpenoids, glycyrrhizin (1), glycyrrhetic acid-3-O-mono- $\beta$-D-glucuronide (2), and glycyrrhetinic acid (3); and the selected major flavonoids, licochalcone A (4), licochalcone B (5), licochalcone C (6), echinatin (7), isoliquiritin apioside (8), liquiritigenin (9), liquiritin apioside (10) isolated from Glycyrrhizae radix et rhizoma, were investigated in the human intestinal epithelium-like Caco-2 cell monolayer model. Compounds 3, 5-7, and 9 were designated as well-absorbed compounds, 2 and 4 were designated as moderately absorbed ones, and 1, 8, and 10 were assigned for the poorly absorbed ones. The absorption mechanism of well and moderately absorbed compound was mainly passive diffusion to pass through the human intestinal Caco-2 cell monolayer. These findings provided useful information for predicting their oral bioavailability and the clinical application.
\end{abstract}

Keywords: Glycyrrhizae radix et rhizoma; triterpenoids; flavonoids; human intestinal Caco-2 cell monolayer model; passive diffusion

\section{Introduction}

The genus Glycyrrhiza consists of about 30 species with a nearly global distribution, of which about 18 species are found in China. Among them, only three species-named Glycyrrhiza uralensis Fisch., Glycyrrhiza inflata Bat., and Glycyrrhiza glabra L.- have been used as traditional Chinese medicines for the treatment of hepatitis, spasmodic cough, gastric ulcer, etc. [1]. Phytochemical studies showed that over 300 diverse compounds have been identified from the genus Glycyrrhiza [2-5]. Among them, triterpenoids and flavonoids were the two major active substances, exerting a variety of pharmacological activities including antiviral [6-8], anti-inflammatory [9-12], antioxidative [13,14], hepatoprotective [15,16], antimicrobial [17-22], antitumor [23-25], antiallergic [26-28], and potent cytochrome P450 enzyme inhibitory [29] properties. To what extent these components are effective in the human body depends on their bioavailability and metabolism in vivo. As is well-known, 
intestinal permeability is a crucial factor which influences the bioavailability of drugs, especially for those oral ones. Therefore, rationalizing intestinal permeability of these components is a critical step towards understanding their potential bioactivity. The focus of this study was to investigate the transport and cellular uptake of three major triterpenoids; glycyrrhizin (1), glycyrrhetic acid-3-O-mono- $\beta$-D-glucuronide (2) and glycyrrhetinic acid (3), and seven flavonoids; licochalcone A (4), licochalcone B (5), licochalcone C (6), echinatin (7), isoliquiritin apioside (8), liquiritigenin (9), and liquiritin apioside (10), whose chemical structures are shown in Figure 1, isolated from Glycyrrhizae radix et rhizoma, in Caco-2 cell monolayer model [30-32], and to predict human intestinal absorption and cellular accumulation of these compounds.

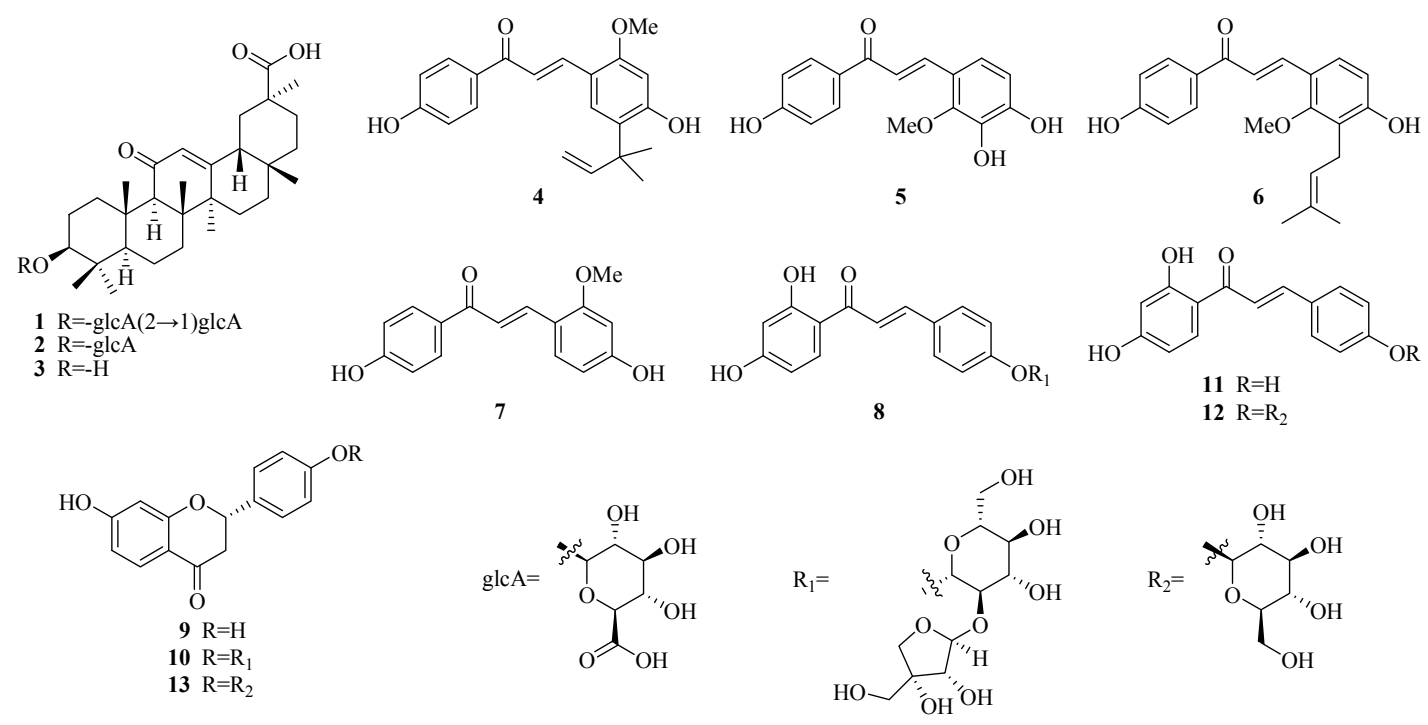

Figure 1. The structures of compounds 1-10 isolated from Glycyrrhizae radix et rhizoma and three related compounds 11-13.

\section{Results and Discussion}

\subsection{Validation of the Caco-2 Cell Monolayer}

The integrity of differentiated Caco- 2 cell monolayer was examined by measuring the transepithelial electrical resistance (TEER) with an epithelial voltohmmeter (EVOM, World Precision Instrument, Sarasota, FL, USA). Only cell monolayers with a TEER value above $500 \Omega \cdot \mathrm{cm}^{2}$ were used for transport assays [31,32]. The apparent permeability coefficients $\left(P_{\text {app }}\right)$ values of propranolol and atenolol, the well- and poor-transported markers by passive diffusion mechanism across Caco-2 cell monolayer, were assessed as $(2.51 \pm 0.21) \times 10^{-5} \mathrm{~cm} / \mathrm{s}$ and $(2.35 \pm 0.11) \times 10^{-7} \mathrm{~cm} / \mathrm{s}$, respectively. The results were in a good agreement with the reported values [32], indicating that the applicability of the cell monolayer as in vitro intestinal absorption model was verified. 3-(4,5-Dimethyl-2-thiazolyl)-2,5-diphenyl-2H-tetrazolium bromide (MTT) assays [32] showed that all compounds at their maximum test concentration exerted no significant influences on the cell viability.

\subsection{Validation of High Performance Liquid Chromatography Analysis Method}

The high performance liquid chromatography (HPLC) analysis methods for the all test compounds had been validated. The standard calibration curves were constructed by plotting peak area $(y)$ versus concentration $(x, \mu \mathrm{M})$. Regression equations, coefficient correlations $\left(r^{2}\right)$, and concentration ranges of the calibration curve for the test compounds were listed in Supplemental Materials (Table S1). The methodological evaluation including the precision, accuracy, and method recovery were summarized in Table S2. The HPLC method was confirmed to be compliant with the Guidance for Industry Bioanalytical Method Validation of FDA [33]. The HPLC method validations of compounds 
$\mathbf{1}, \mathbf{8}$, and 10 were not performed, because they were extremely difficult to transport through Caco-2 cell monolayer.

\subsection{Bidirectional Transport Determination}

\subsubsection{Bidirectional Transport of Triterpenoids 1-3}

The bilateral (apical side $(\mathrm{AP}) \rightarrow$ basolateral side $(\mathrm{BL})$ and $\mathrm{BL} \rightarrow \mathrm{AP}) P_{\text {app }}$ values of triterpenoids 1-3 are summarized in Table 1. Compound $\mathbf{1}$ was not detected in the receiving sides after incubation for 90 min in both $\mathrm{AP} \rightarrow \mathrm{BL}$ and $\mathrm{BL} \rightarrow \mathrm{AP}$ transports, indicating that compound $\mathbf{1}$ was very poorly absorbed. Whereas the $P_{\text {app }}$ values of compound 3 were well over $10^{-5} \mathrm{~cm} / \mathrm{s}$, which was comparable to that of propranolol $\left((2.51 \pm 0.21) \times 10^{-5} \mathrm{~cm} / \mathrm{s}\right)$, a well-transported marker of the transcellular pathway [32], so compound 3 was designated as a well-absorbed compound. The $P_{\text {app }}$ values of compound 2 in the bidirectional transportation were of $1 \times 10^{-6} \mathrm{~cm} / \mathrm{s}$ magnitude, which lay between that of propranolol and atenolol, so compound $\mathbf{2}$ was designated as a moderately absorbed compound.

Table 1. The bidirectional $P_{\text {app }}$ values of compounds 1-13 in Caco-2 cell monolayer $(n=3) .{ }^{\text {a }}$

\begin{tabular}{|c|c|c|c|c|c|}
\hline Analytes & $\begin{array}{l}P_{\text {app AP } \rightarrow \text { BL }} b \\
\left(\times 10^{-6} \mathrm{~cm} / \mathrm{s}\right)\end{array}$ & $\begin{array}{l}P_{\text {app BL } \rightarrow \text { AP }}{ }^{\mathrm{c}} \\
\left(\times 10^{-6} \mathrm{~cm} / \mathrm{s}\right)\end{array}$ & Efflux Ratio $^{d}$ & MW & $\begin{array}{c}\log D \\
(\mathrm{pH}=7.35)\end{array}$ \\
\hline 1 & 0 & 0 & - & 822 & -8.02 \\
\hline 2 & $1.55 \pm 0.09$ & $1.65 \pm 0.95$ & 1.06 & 646 & -2.94 \\
\hline 3 & $12.63 \pm 0.40$ & $14.00 \pm 1.30$ & 1.11 & 470 & 2.57 \\
\hline 4 & $1.68 \pm 0.13$ & $1.78 \pm 0.03$ & 1.06 & 338 & 4.48 \\
\hline 5 & $24.71 \pm 2.80$ & $30.18 \pm 2.40$ & 1.22 & 286 & 2.91 \\
\hline 6 & $22.51 \pm 1.00$ & $26.44 \pm 1.30$ & 1.17 & 338 & 4.62 \\
\hline 7 & $20.70 \pm 1.00$ & $23.80 \pm 0.30$ & 1.15 & 270 & 3.43 \\
\hline 8 & 0 & 0 & - & 550 & -0.94 \\
\hline 9 & $17.80 \pm 0.60$ & $15.68 \pm 0.30$ & 0.88 & 256 & 2.95 \\
\hline 10 & 0 & 0 & - & 550 & -0.23 \\
\hline 11 & $14.60 \pm 0.10$ & $9.35 \pm 0.43$ & 0.64 & 256 & 2.50 \\
\hline 12 & $0.87 \pm 0.02$ & $0.77 \pm 0.07$ & 0.89 & 418 & -0.48 \\
\hline 13 & $0.54 \pm 0.02$ & $0.53 \pm 0.03$ & 0.98 & 418 & 0.02 \\
\hline
\end{tabular}

a The incubation time was up to $90 \mathrm{~min} .{ }^{\mathrm{b}}$ Transport of assayed compounds from AP to BL direction. ${ }^{\mathrm{c}}$ Transport of assayed compounds from BL to AP direction. ${ }^{\mathrm{d}}$ The ratio of $P_{\mathrm{app} B \mathrm{BL} \rightarrow \mathrm{AP}}$ to $P_{\mathrm{app}} \mathrm{AP} \rightarrow \mathrm{BL}$.

Compound $\mathbf{3}$ is a triterpenoid aglycone, while compounds $\mathbf{1}$ and $\mathbf{2}$ are $\mathrm{C}_{3}-\mathrm{O}-\beta-\mathrm{D}-$ bisglucopyranuronoside and $\mathrm{C}_{3}-\mathrm{O}-\beta-\mathrm{D}$-monoglucopyranuronoside of $\mathbf{3}$ (Figure 1), respectively. Apparently, reducing the number of sugar moieties increased the membrane permeability. Compound 1 displayed very poor intestinal absorption that may be attributed to poor membrane permeability. The comparable bidirectional $P_{\text {app }}$ values (a ratio of $1.06-1.11$ for $P_{\text {app BL } \rightarrow \mathrm{AP}} / P_{\text {app AP } \rightarrow \mathrm{BL}}$ ) of compounds 2 and 3 suggested passive diffusion as the main transport mechanism. It has been demonstrated in many reports that compound 1 shows substantial pharmacological effects $[2,6]$. On the other hand, it has also been revealed that compound $\mathbf{1}$ can be transformed to compounds $\mathbf{2}$ and $\mathbf{3}$ by intestinal bacteria following the oral intake of licorice in humans [34]. Therefore, predictions could be made that the compounds 2 and $\mathbf{3}$ were absorbed in blood as the active metabolite of licorice, especially compound 3.

\subsubsection{The Time Course and Concentration-Dependence of Permeation of Triterpenoids 2 and 3}

The bilateral permeation of compounds 2 and 3 increased approximately linearly with time (0-180 $\mathrm{min}$ ) at $50 \mu \mathrm{M}$ (Figure 2), and the rates of membrane permeation increased approximately linearly at $90 \mathrm{~min}$ (Figure 2) within the test range of concentration (10-175 $\mu \mathrm{M}$ for compound 2 and 2.5-75 $\mu \mathrm{M}$ for compound 3). From kinetic curves presented in Figure 3, the amount of compounds 2 and 3 decreased approximately linearly in AP side and increased approximately linearly in BL side within the incubation time. 

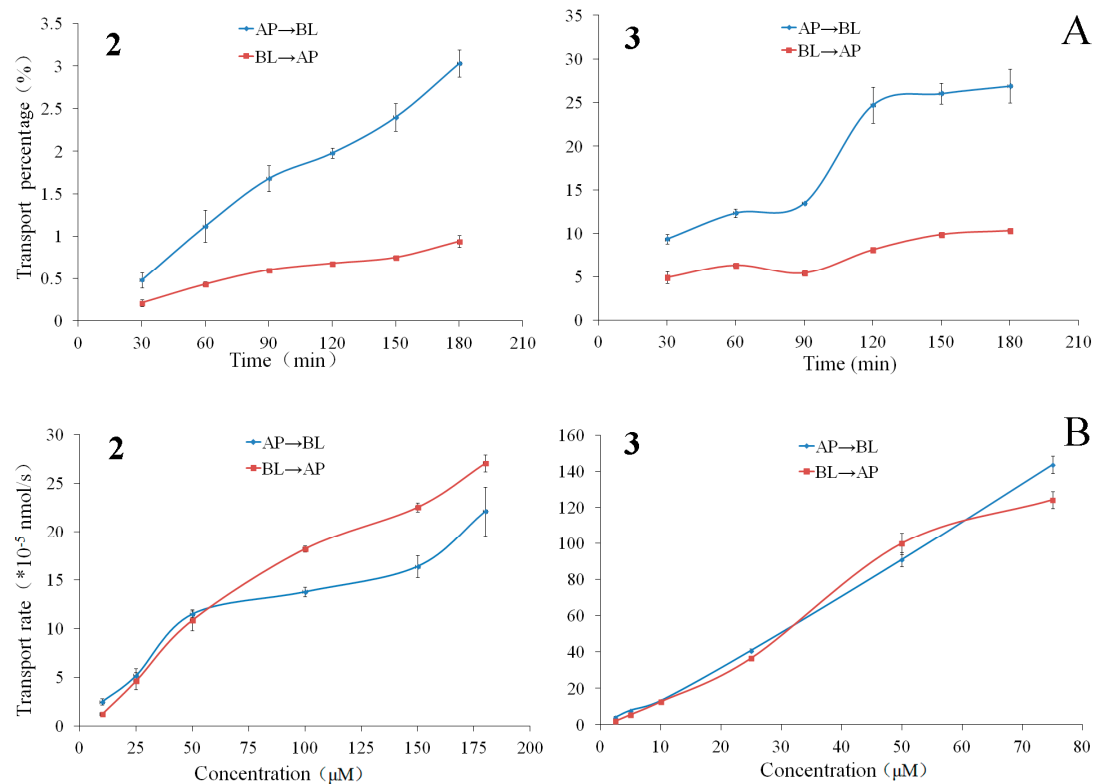

Figure 2. The transport percentage as a function of time at $50 \mu \mathrm{M}(\mathbf{A})$ and transport rates as a function of concentration at $90 \mathrm{~min}$ (B) of the compounds 2 and 3 in Caco-2 cell monolayer. Data are the mean $\pm \mathrm{SD}(n=3)$.
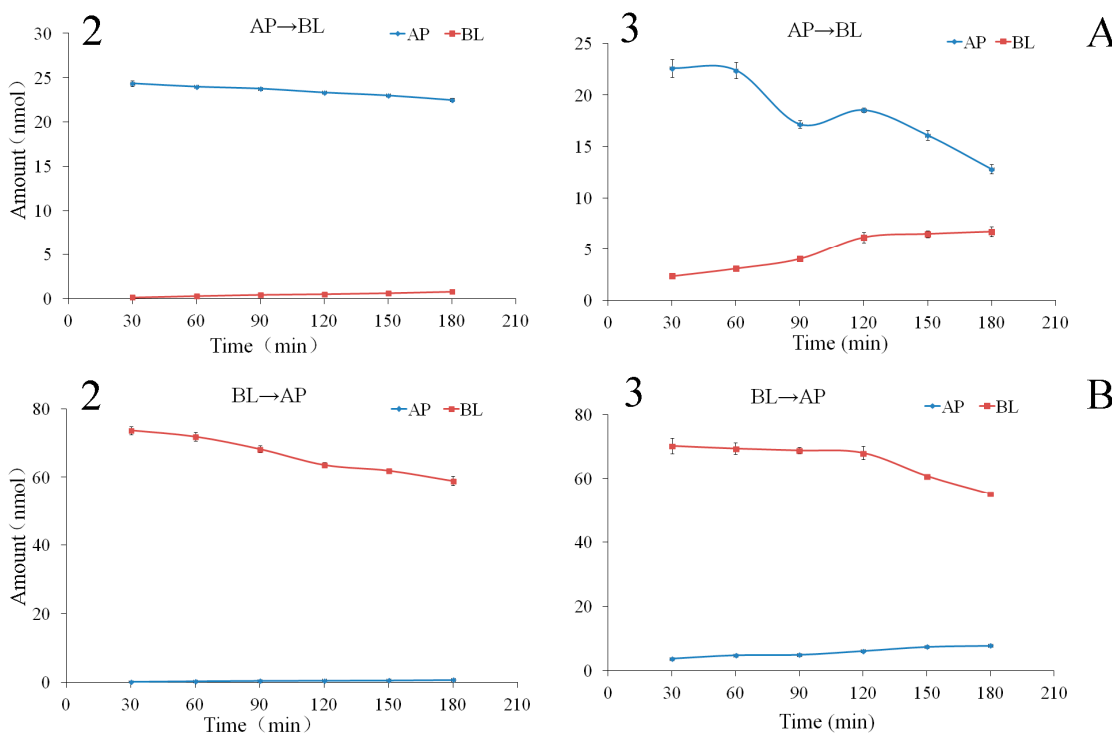

Figure 3. Kinetics curves of the compounds 2 and 3 transports in Caco-2 monolayer from apical to basolateral direction at $50 \mu \mathrm{M}$. (A) $\mathrm{AP} \rightarrow \mathrm{BL},(\mathbf{B}) \mathrm{BL} \rightarrow \mathrm{AP}$. Data are the mean $\pm \mathrm{SD}(n=3)$.

\subsubsection{Bidirectional Transport of Chalcones $4-8$}

The bidirectional $P_{\text {app }}$ values of chalcones 4-8 are summarized in Table 1. Chalcones 5-7 were designated as well-absorbed compounds, while chalcones $\mathbf{4}$ and $\mathbf{8}$ were designated as a moderately and poorly absorbed compounds, respectively. The $P_{\text {app }}$ values of chalcone $\mathbf{1 1}$ (isoliquiritigenin) were reported to be $(1.46 \pm 0.01) \times 10^{-5} \mathrm{~cm} / \mathrm{s}$ from AP to BL direction and $(9.35 \pm 0.43) \times 10^{-6} \mathrm{~cm} / \mathrm{s}$ from BL to AP direction [35], and those of chalcone 12 (isoliquiritin) were reported to be $(8.69 \pm 0.15) \times 10^{-7} \mathrm{~cm} / \mathrm{s}$ from AP to BL direction and $(7.68 \pm 0.66) \times 10^{-7} \mathrm{~cm} / \mathrm{s}$ from BL to AP direction in our previous papers [36]. The results indicated that chalcone aglycones were well or moderately absorbed 
compounds. Whereas the magnitude of the bidirectional $P_{\text {app }}$ values of chalcone glycosides (chalcones 12 and 8) were $1 \times 10^{-7} \mathrm{~cm} / \mathrm{s}$ or below, they were designated as the poorly absorbed compounds.

\subsubsection{The Time Course and Concentration-Dependence of Membrane Permeation of Chalcones 4-7}

The bilateral permeation of the chalcones 4-7 increased approximately linearly with time (0-180 $\mathrm{min}$ ) at $50 \mu \mathrm{M}$ (Figure 4), while the rates of membrane permeation increased approximately linearly at $90 \mathrm{~min}$ (Figure 4) within the test range of concentration (2.5-100 $\mathrm{MM}$ for chalcone 4, 10-150 $\mu \mathrm{M}$ for chalcone 5, 10-200 $\mu \mathrm{M}$ for chalcones 6 and 7). From kinetic curves presented in Figure 5, the amount of the chalcones 4-7 decreased in AP side and increased in BL side approximately linearly within the incubation time.
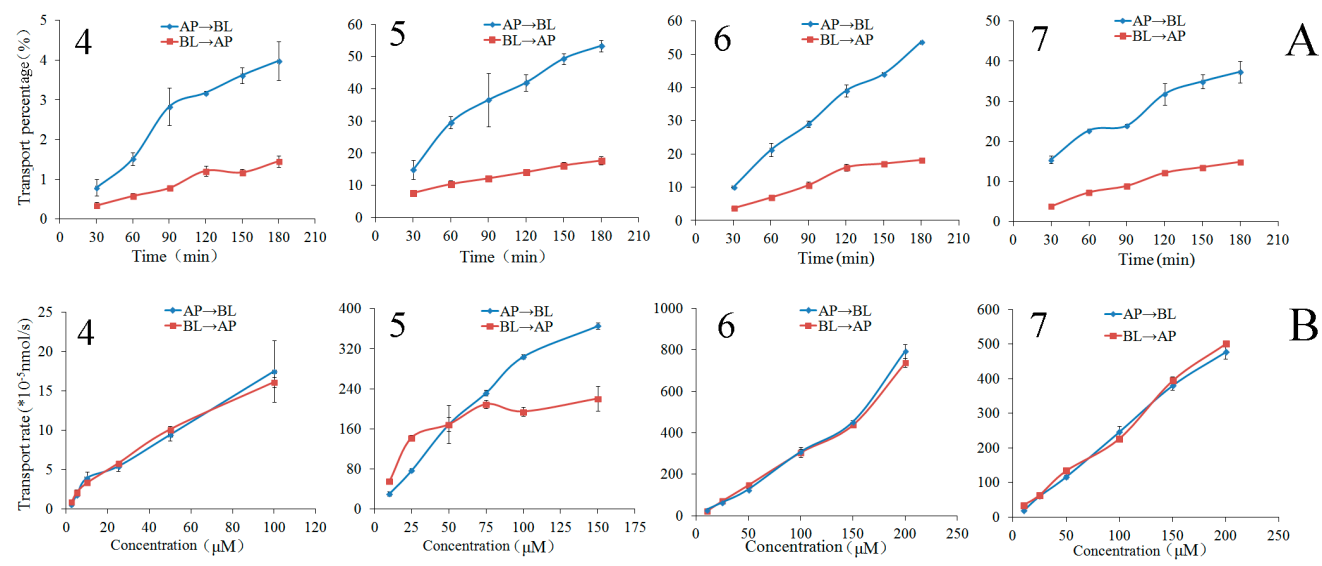

Figure 4. The transport percentage as a function of time at $50 \mu \mathrm{M}(\mathrm{A})$ and transport rates as a function of concentration at $90 \mathrm{~min}(\mathbf{B})$ of the chalcones 4-7 in Caco-2 cell monolayer. Data are the mean $\pm \mathrm{SD}$ $(n=3)$.
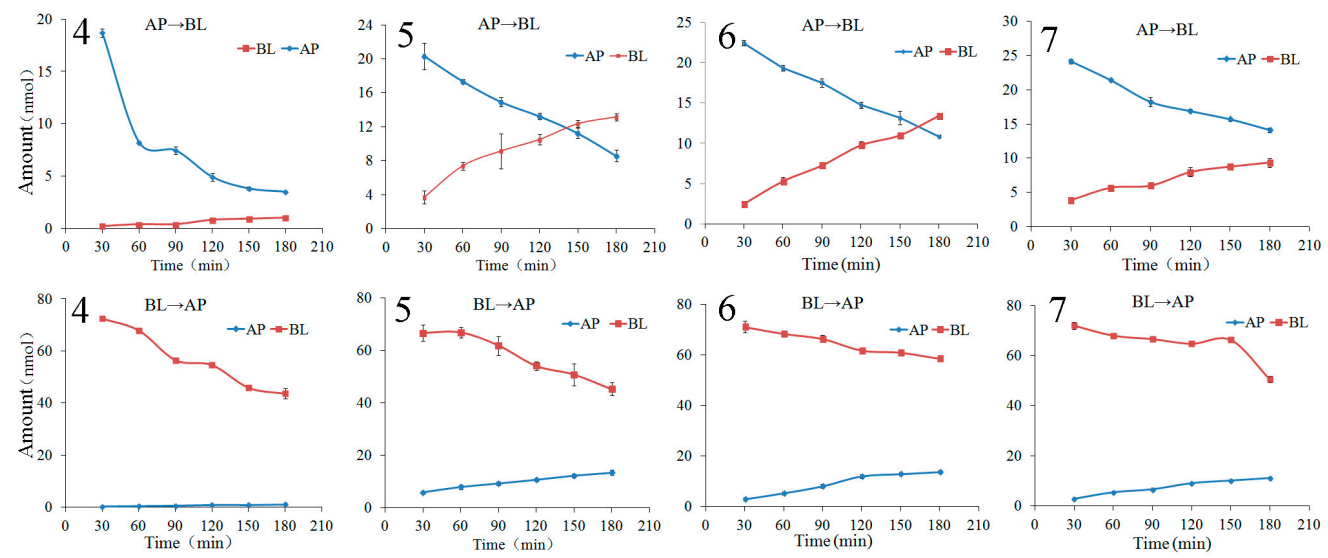

Figure 5. Transport kinetics curves of the chalcones 4-7 in Caco-2 monolayer from apical to basolateral direction at $50 \mu \mathrm{M}$. Data are the mean $\pm \mathrm{SD}(n=3)$.

\subsubsection{Bidirectional Transport of Flavonones $\mathbf{9}$ and $\mathbf{1 0}$}

The bidirectional $P_{\text {app }}$ values of flavonones $\mathbf{9}$ and $\mathbf{1 0}$ are summarized in Table 1. Flavonone 9 was assigned as a well-absorbed compound with $P_{\text {app }}$ value of around $1 \times 10^{-5} \mathrm{~cm} / \mathrm{s}$. Flavonone 10 was found to hardly permeate Caco- 2 cell monolayer with $P_{\text {app }}$ value $<1 \times 10^{-7} \mathrm{~cm} / \mathrm{s}$. The $P_{\text {app }}$ values of flavonone 13 (liquiritin) were reported to be $(5.40 \pm 0.16) \times 10^{-7} \mathrm{~cm} / \mathrm{s}$ from AP to BL direction and $(5.32 \pm 0.31) \times 10^{-7} \mathrm{~cm} / \mathrm{s}$ from BL to AP direction in our previous study [36], and it was designated as a poorly absorbed compound. The decreasing order of the permeability was 
$9>13>10$, i.e., disaccharide glycoside (10) showed less permeability than monosaccharide glycoside (13), and both of them had far less permeability than the corresponding aglycone (9). This was in accordance with the finding in the case of triterpenoids 1-3 that the permeability of compounds in the Caco-2 cell monolayer can be reduced with the increase in the number of glycosyl groups on the core molecular nuclei.

\subsubsection{The Time Course and Concentration-Dependence of Permeation of Flavonone 9}

The bilateral permeation of the flavonone 9 increased approximately linearly with time (0-180 $\mathrm{min})$ at $50 \mu \mathrm{M}$ (Figure 6), while the rates of permeation increased approximately linearly at 90 min (Figure 6) within the test range of concentration $(10-200 \mu \mathrm{M})$. From kinetic curves presented in Figure 6, the amount of the flavonone 9 in AP side decreased approximately linearly and in BL side increased approximately linearly within the incubation time.
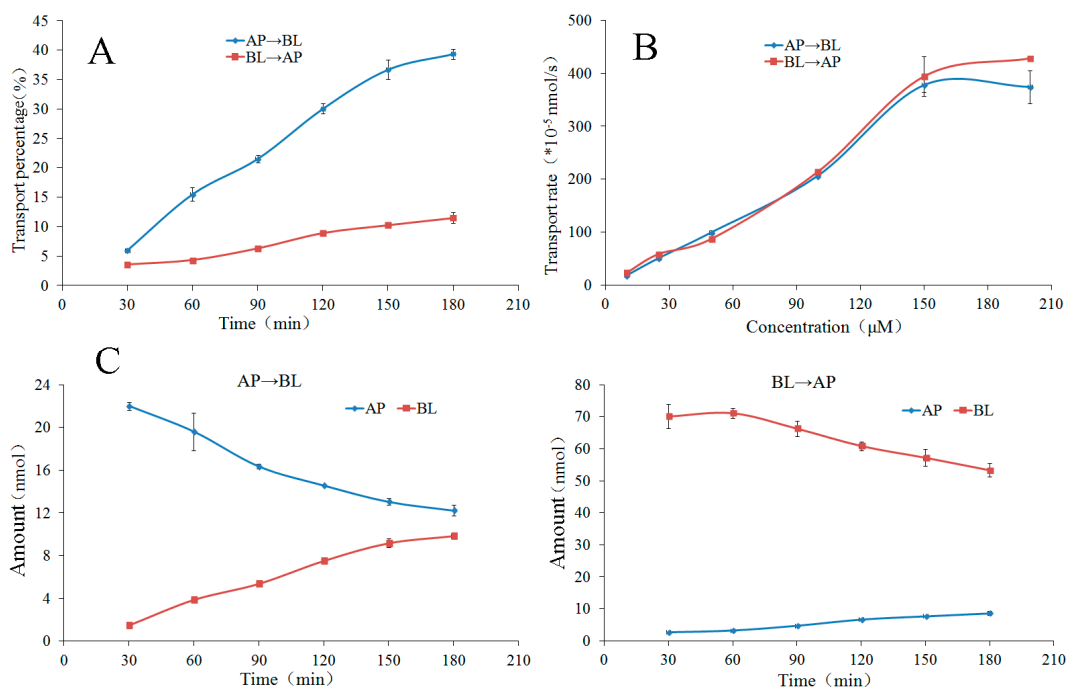

Figure 6. The transport percentage as a function of time at $50 \mu \mathrm{M}(\mathbf{A})$, transport rate as a function of concentration at $90 \mathrm{~min}(\mathbf{B})$ and transport kinetics curves $(\mathbf{C})$ of the flavonone 9 in Caco-2 monolayer. Data are the mean $\pm \mathrm{SD}(n=3)$.

At the end of the transport experiments, the mass balance was calculated (see Supplementary data, Table S3). The recoveries of compounds 2, 3, 5-7, and 9 were $85.06-98.24 \%$ in all bidirectional transport studies with very low cell accumulation. This suggests no significant first-pass metabolism during their intestinal absorption and transport. The recovery of compound 4 was relatively lower in the $\mathrm{AP} \rightarrow \mathrm{BL}$ transport with the higher intracellular uptake in all bidirectional transport. The efflux ratios (Table 1 ) of the compounds $2-7$, and 9 were within the range of $0.88-1.22$, suggesting that their bidirectional transport was comparable and lack of directional preference. The results of the concentration-dependency presented in Figures 2, 4 and 6 suggested a passive diffusion mechanism of compounds 2-7, and 9 across the Caco- 2 cell monolayer. The kinetics curves for time-dependency (Figures 2, 4 and 6) indicated no efflux or active transport and again confirmed the passive diffusion mechanism. In general, the passively transported compounds with $P_{\text {app AP } \rightarrow B L}$ values $>1 \times 10^{-6} \mathrm{~cm} / \mathrm{s}$ can cross the intestinal barrier efficiently with the percentage of absorption $>20 \%$ [32]. $P_{\text {app AP } \rightarrow \mathrm{BL}}$ values of compounds $2-7$, and 9 all exceeded $1 \times 10^{-6}$, predicting that they would be absorbed in human intestine.

Physicochemical characters such as log D (logarithm of octanol-water partition coefficient) and MW (molecular weight) were generally utilized for the prediction of the permeability of compounds [37]. An analysis of the relationship between the $\log \mathrm{D}, \mathrm{MW}$, and the determined $P_{\text {app }}$ value of different kinds of compounds may help to rich the predictive database. The log $\mathrm{D}$ values 
at pH 7.35 of compounds 1-13, calculated with Pallas 3.3.2.6 ADME/Tox Software (CompuDrug, Bal Harbor, FL, USA), as well as their MW values were shown in Table 1 . Herein, a sigmoid trendline of $\log \left(P_{\text {app AP } \rightarrow \mathrm{BL}} \times \mathrm{MW}^{1 / 2}\right)$ versus $\log \mathrm{D}$ was plotted (Figure 7$)$ with Origin Pro 7.5 SR1 (Origin Lab. Corporation, Northampton, MA, USA) to elucidate the structure-permeability relationship of chalcones 4-8, 11, and 12. It was found that the permeability of chalcones increased in the log D range of $-1-3$, which was consistent with the common regulation that the more lipophilicity one compound shows, the more permeability it has; however, those of chalcones kept nearly invariable in the $\log \mathrm{D}$ range of 3-5, which led to a higher permeability with the exception of chalcones 4 .

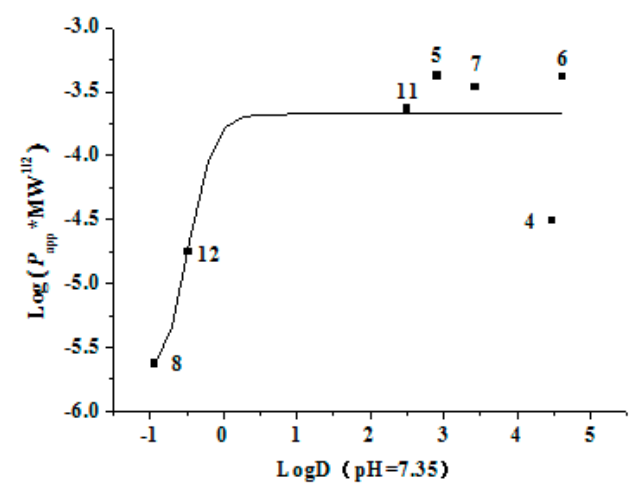

Figure 7. The relationship between $\log \left(P_{\mathrm{app} \mathrm{AP} \rightarrow \mathrm{BL}} \times \mathrm{MW}^{1 / 2}\right)$ and $\log \mathrm{D}(\mathrm{pH}=7.35)$ for seven chalcones $(4-8,11$, and 12).

\section{Experimental Section}

\subsection{Assayed Compounds}

Triterpenoids glycyrrhizin (1), glycyrrhetic acid-3-O-mono- $\beta$-D-glucuronide (2), and glycyrrhetinic acid (3) were supplied by Natural Product Sample Library in State Key Laboratory of Natural and Biomimetic Drugs of Peking University (Beijing, China). Chalcones licochalcone A (4), licochalcone B (5), licochalcone C (6), and echinatin (7) were obtained from Tianjin Chroma-standard Medical Science \& Technology Development Co. Ltd. (Tianjin, China), and isoliquiritin apioside (8) was obtained from Shanghai Tauto Biotech Co. Ltd. (Shanghai, China). Flavonones liquiritigenin (9) and liquiritin apioside (10) were obtained from Shanghai Tauto Biotech Co. Ltd. (Shanghai, China).

\subsection{Chemicals and Reagents}

HPLC grade methanol (MeOH) was purchased from Fisher Scientific (Fair lawn, NJ, USA). Analytical grade acetic acid and Hank's Balanced Salts Solution (HBSS) were purchased from Beijing Chemical Works (Beijing, China). Water was purified by a Mili-system (Millipore, Bedford, MA, USA). Propranolol, atenolol and dimethyl sulfoxide (DMSO) were purchased from Sigma-Aldrich Co. (St. Louis, MO, USA). Penicillin-streptomycin solution was obtained from Suolaibao Technology Ltd. (Beijing, China). Dulbecco's Modified Eagle's Medium (DMEM), fetal bovine serum (FBS), phosphate buffered saline (PBS), nonessential amino acids (NEAA), and trypsin were supplied by Gibco ${ }^{\circledR}$ Laboratories (Life Technologies Inc., Grand Island, NY, USA).

\subsection{Instrumental Analyses}

Quantitative analysis of compounds 2-7 and 9 was performed on a Dionex Ultimate ${ }^{\mathrm{TM}} 3000$ UHPLC system (Dionex Corp., Sunnyvale, CA, USA), comprised of Ultimate 3000 pump, autosampler, column compartment, and diode array detector. The signals were acquired and processed applying a Chromeleon version 6.80 software (Dionex Corp., Sunnyvale, CA, USA). HPLC separation was performed on a Dikma Diamonsil ${ }^{\mathrm{TM}} \mathrm{C}_{18}$ column $(250 \mathrm{~mm} \times 4.6 \mathrm{~mm}, 5 \mu \mathrm{m}$, Dikma Technology, Inc., 
Beijing, China). The mobile phase was consisted of $\mathrm{MeOH}$ and $0.6 \%$ acetic acid in aqueous solution $(v / v)$ in 81:19 for compound 2, 86:14 for compound 3, 70:30 for compound 4, 45:55 for compounds 5, 6, and 9, 50:50 for compound 7, with a flow rate of $1 \mathrm{~mL} / \mathrm{min}$, a column temperature of $30{ }^{\circ} \mathrm{C}$ and a injected volume of $10 \mu \mathrm{L}$ for compounds 2-7 and 9. The detection wavelength was set at $254 \mathrm{~nm}$ for compounds 2 and 3, $372 \mathrm{~nm}$ for compound 4, $360 \mathrm{~nm}$ for compound 5, $276 \mathrm{~nm}$ for 6, $370 \mathrm{~nm}$ for 7, and $276 \mathrm{~nm}$ for compound 9 . The calibration curves were constructed by plotting peak area $(y)$ versus concentration $(x, \mu \mathrm{M})$, which concentration series $(\mu \mathrm{M})$ were $5,25,50,75,150,200$ for compound $2 ; 2.5$, $5,10,15,25,50$ for compound $3 ; 5,10,15,25,50,75$ for compound $4 ; 2.5,5,10,25,50,75$ for compound $5 ; 5,10,25,50,75,150$ for compound $6 ; 10,25,50,75,150,200$ for compound 7; 5, 10, 25, 75, 100, 200 for compound 9. The amounts of compounds $\mathbf{1}, \mathbf{8}$, and $\mathbf{1 0}$ in the receiving chambers were below the lower limit of detection (LLOD). Quantification was carried out by peak area measurements in comparison with the calibration curves. Methodology was examined for precision, accuracy, and recovery (see Supplemental Material Table S1) and was demonstrated to meet the requirements of determination.

\subsection{Cell Culture}

The human intestinal Caco-2 cell line (ATCC \#HTB-37) was purchased from American Type Culture Collection (ATCC, Rockville, MD, USA). The cell culture was carried out in a Sanyo MCO-15 AC carbon dioxide $\left(\mathrm{CO}_{2}\right)$ incubator (Sanyo Electric Co., Ltd., Osaka, Japan). The integrity of the Caco-2 cell monolayer was examined by measuring the TEER with an epithelial voltohmmeter (EVOM, World Precision Instrument, Sarasota, FL, USA) [32]. All cells used in this study were between passages 30 and 40 .

\subsection{Caco-2 Cell Permeability}

The Caco-2 cell monolayer permeability was carried out according to the previously reported method [32,38]. Briefly, the Caco-2 cells were maintained in DMEM containing 10\% FBS, 1\% NEAA, 100 units $/ \mathrm{mL}$ of penicillin, and $100 \mu \mathrm{g} / \mathrm{mL}$ of streptomycin, in a constant humidity atmosphere of $5 \% \mathrm{CO}_{2}$ and $95 \%$ air at $37{ }^{\circ} \mathrm{C}$. For confluence and differentiation, cells were seeded at a density of $1 \times 10^{5}$ cells $/ \mathrm{cm}^{2}$ into 12-well Transwell plates (insert diameter $12 \mathrm{~mm}$, pore size $3.0 \mu \mathrm{m}$, membrane growth area $1.12 \mathrm{~cm}^{2}$, Costar $^{\circledR} \# 3402$ ) and were allowed to grow for 21 days before the permeation experiment. On day 21, the monolayers with TEER values $>500 \Omega \cdot \mathrm{cm}^{2}$ were qualified for the transport experiment. The transport study was initiated by the careful removal of the culture medium from AP and BL sides of the inserts. Caco-2 monolayers were rinsed twice with pre-warmed HBSS and were incubated by pre-warmed HBSS for $30 \mathrm{~min}$ at $37^{\circ} \mathrm{C}$. Stock solutions of assayed compounds 1-10 were prepared in DMSO and diluted to $50 \mu \mathrm{M}$ with HBSS. The final DMSO concentration was less than $2 \%$, a concentration that did not alter the Caco-2 cells viability or permeability. The assayed solutions $(50 \mu \mathrm{M})$ were added to the AP side $(0.5 \mathrm{~mL}$, for absorption transport) or BL side $(1.5 \mathrm{~mL}$, for efflux transport) of the inserts, while the receiving chamber contained the corresponding volume of HBSS. Incubation was performed at $37^{\circ} \mathrm{C}$ for $90 \mathrm{~min}$, with shaking at $50 \mathrm{rpm}$. Samples were collected from the inserts and lyophilized. The dried sample was then sonicated with the appropriate volume of $\mathrm{MeOH}$, followed by centrifugation at $15,000 \times g$ for $10 \mathrm{~min}$. The supernatant was filtered through a $0.45 \mu \mathrm{m}$ filter and injected into HPLC system for quantitative analysis.

The AP to BL or BL to AP permeability coefficient $\left(P_{\text {app }}\right)$ value of each compound was calculated based on the following equation:

$$
P_{\text {app }}=(\mathrm{dQ} / \mathrm{dt}) \times(1 / \mathrm{A}) \times\left(1 / \mathrm{C}_{0}\right)(\mathrm{cm} / \mathrm{s})
$$

where $\mathrm{dQ} / \mathrm{dt}$ is the rate of the appearance of the test compound on the receiver compartment $(\mu \mathrm{mol} / \mathrm{s})$, $\mathrm{C}_{0}$ is the initial test compound concentration on the donor compartment ( $\left.\mu \mathrm{mol} / \mathrm{mL}\right)$, and $\mathrm{A}$ is the surface area of Caco-2 monolayer $\left(\mathrm{cm}^{2}\right)$. 


\subsection{Time- and Concentration-Dependent Transport of the Compounds 2-7 and $\mathbf{9}$ across the Caco-2 Cell Monolayer}

To observe the time-dependence, $50 \mu \mathrm{M}$ of the compounds 2-7 and 9 were added to either AP or $\mathrm{BL}$ side of the inserts. While shaking the samples $\left(37^{\circ} \mathrm{C}, 50 \mathrm{rpm}\right), 1.3 \mathrm{~mL}$ aliquots were taken from $\mathrm{BL}$ side or $0.45 \mathrm{~mL}$ aliquots were taken from AP side at $30 \mathrm{~min}$ intervals from 30 to $180 \mathrm{~min}$.

To observe the concentration-dependence, the compounds 2-7 and $\mathbf{9}$ were added to either AP or $\mathrm{BL}$ side of the inserts at the final concentration in the range of 10-175 $\mu \mathrm{M}$ for compound 2, 2.5-75 $\mu \mathrm{M}$ for compound 3, 2.5-100 $\mu \mathrm{M}$ for compound 4, 10-150 $\mu \mathrm{M}$ for compound 5, 10-200 $\mu \mathrm{M}$ for compounds 6, 7, and 9. After shaking the samples $\left(37^{\circ} \mathrm{C}, 50 \mathrm{rpm}\right)$ in a shaking water bath for $90 \mathrm{~min}$, aliquots were collected as described above. As in the case of time-dependent transport experiments, the kinetics curves of the compounds 2-7 and 9 were drawn at an initial concentration of $50 \mu \mathrm{M}$ and intervals from 30 to $180 \mathrm{~min}$.

\subsection{Intracellular Accumulation and Recovery}

To measure the amount of intracellular accumulation, the Caco-2 cells were rinsed three times with ice-cold HBSS at the end of transport experiments. After three freeze $\left(-20{ }^{\circ} \mathrm{C}\right)$-thaw (room temperature) cycles, the lysed Caco- 2 cells were lyophilized. The dried cells were sonicated in $0.2 \mathrm{~mL}$ of $70 \%$ aqueous $\mathrm{MeOH}$ for $20 \mathrm{~min}$ and then centrifuged at $15,000 \times g$ for $10 \mathrm{~min}$. The supernatant was filtered through a $0.45 \mu \mathrm{m}$ filter and a $10 \mu \mathrm{L}$ aliquot was injected into the HPLC system for analysis. To check the mass balance, the recoveries of the assayed compounds were measured at both sides of the insert and intracellular accumulation of the Caco-2 cells.

\section{Conclusions}

The transport rates of the six selected compounds 3, 5-7, and 9, lipophilic aglycones including major triterpenoid, chalcone, and flavonone compounds in licorice, increased linearly with the concentration and saturation was not observed at the concentrations tested, indicating that the permeation mechanism for these compounds was passive diffusion. The magnitude of the bidirectional flux of these compounds was comparable to propranolol $\left(P_{\text {app }}=(2.51 \pm 0.21) \times 10^{-5} \mathrm{~cm} / \mathrm{s}\right)$. These data suggest that the compounds 3,5-7, and 9 were well-absorbed compounds and were transported mainly through passive diffusion by the transcellular pathway. The recoveries of compounds 3, 5-7, and 9 were higher in bidirectional transport studies with very low cell accumulation, suggesting metabolism may not be involved during their intestinal absorption and transport. In spite of the fact that chalcone 4 was also an aglycone, the higher accumulation in Caco- 2 cells resulted in its $P_{\text {app }}$ value laying between $P_{\text {app }}$ values of propranolol and atenolol, and chalcone 4 was designated as a moderately absorbed compound. Permeation of the bisglycosides 1, 8, and 10, across the Caco-2 cell monolayer was not detected, suggesting their $P_{\text {app }}$ values less than $1 \times 10^{-7} \mathrm{~cm} / \mathrm{s}$, and they were designated as the very poorly absorbed compounds. While the monoglycosides 2 with $1 \times 10^{-6} \mathrm{~cm} / \mathrm{s}$ degree of $P_{\text {app }}$ value, 12 and 13 with $1 \times 10^{-7} \mathrm{~cm} / \mathrm{s}$ degree of $P_{\text {app }}$ value [36] were designated as the moderately or poorly absorbed compounds, indicating that the number of sugar groups linked in aglycone molecule was one of the important factors to affect their intestinal absorption by comparison with the corresponding aglycone. In addition, analysis on the relationship between the $\log \mathrm{D}, \mathrm{MW}$, and the determined $P_{\text {app }}$ value of different kinds of compounds may help to rich the predictive database of drug ADME/T. These new findings provided useful information for predicting their oral bioavailability, pharmacokinetics, and the clinical application as well as determination of the bioactive substance basis of Glycyrrhizae radix et rhizoma $[39,40]$.

Supplementary Materials: Supplementary materials are available online: Table S1 for regression data of compounds 2-7 and 9. Table S2 for precision, accuracy and recovery of compounds 2-7 and 9. Table S3 for the total recovery and the intracellular accumulation percentage of the assayed compounds 2-7 and 9 from the Caco- 2 cell monolayer at the end of transport. 
Acknowledgments: This research was partly supported by the National Natural Science Foundation of China (81530097) and the National Key Technology R \& D Program of China (2011BAI07B08).

Author Contributions: The list authors contributed to this work as follows: X.-W.Y. and G.-Y.L. conceived and designed the experiments; X.-X.W., Y.-F.Y., X.-W.W., and W.X. performed the experiments and analyzed the data; X.-X.W., G.-Y.L., and X.-W.Y. wrote the paper; X.-W.Y. and G.-Y.L. acquired funding for the research. All authors read and approved the final manuscript.

Conflicts of Interest: The authors declare no conflict of interest.

\section{References}

1. Chinese Pharmacopoeia Commission. Pharmacopoeia of the People's Republic of China, 1st ed.; China Medical Science and Technology Press: Beijing, China, 2015; Volume I, pp. 86-87. ISBN 978-7-5067-7337-9.

2. Zhang, Q.Y.; Ye, M. Chemical analysis of the Chinese herbal medicine Gan-Cao (licorice). J. Chromatogr. A 2009, 1216, 1954-1969. [CrossRef] [PubMed]

3. Qiao, X.; Song, W.; Ji, S.; Wang, Q.; Guo, D.A.; Ye, M. Separation and characterization of phenolic compounds and triterpenoid saponins in licorice (Glycyrrhiza. uralensis) using mobile phase-dependent reversed-phase $\times$ reversed-phase comprehensive two-dimensional liquid chromatography coupled with mass spectrometry. J. Chromatogr. A 2015, 1402, 36-45. [PubMed]

4. Karkanis, A.; Martins, N.; Petropoulos, S.A.; Ferreira, I.C.F.R. Phytochemical composition, health effects, and crop management of liquorice (Glycyrrhiza. glabra L.): A medicinal plant. Food Rev. Int. 2016, 1-22. [CrossRef]

5. Li, W.; Asada, Y.; Yoshikawa, T. Flavonoid constituents from Glycyrrhiza. glabra hairy root cultures. Phytochemistry 2000, 55, 447-456. [CrossRef]

6. Adianti, M.; Aoki, C.; Komoto, M.; Deng, L.; Shoji, I.; Wahyuni, T.S.; Lusida, M.I.; Soetjipto, H.; Fuchino, N.; Hotta Kawahara, H. Anti-hepatitis C virus compounds obtained from Glycyrrhiza. uralensis and other Glycyrrhiza. species. Microbiol. Immunol. 2014, 58, 180-187. [CrossRef] [PubMed]

7. Wolkerstorfer, A.; Kurz, H.; Bachhofner, N.; Szolar, O.H. Glycyrrhizin inhibits influenza A virus uptake into the cell. Antiviral Res. 2009, 83, 171-178. [CrossRef] [PubMed]

8. Ashfaq, U.A.; Masoud, M.S.; Nawaz, Z.; Riazuddin, S. Glycyrrhizin as antiviral agent against hepatitis C virus. J. Transl. Med. 2011, 9, 112. [CrossRef] [PubMed]

9. Fujisawa, Y.; Sakamoto, M.; Matsushita, M.; Fujita, T.; Nishioka, K. Glycyrrhizin inhibits the lytic pathway of complement-possible mechanism of its anti-inflammatory effect on liver cells in viral hepatitis. Micrrobiol. Immunol. 2000, 44, 799-804. [CrossRef]

10. Fu, Y.; Chen, J.; Li, Y.J.; Zheng, Y.F.; Li, P. Antioxidant and anti-inflammatory activities of six flavonoids separated from licorice. Food Chem. 2013, 141, 1063-1073. [CrossRef] [PubMed]

11. Chu, X.; Ci, X.X.; Wei, M.M.; Yang, X.F.; Cao, Q.J.; Guan, M.F.; Li, H.Y.; Deng, Y.H.; Feng, H.H.; Deng, X.M. Licochalcone A inhibits lipopolysaccharide-induced inflammatory response in vitro and in vivo. J. Agric. Food Chem. 2012, 60, 3947-3954. [CrossRef] [PubMed]

12. Li, C.M.; Eom, T.K.; Jeong, Y.H. Glycyrrhiza. glabra L. extract inhibits LPS-induced inflammation in RAW macrophages. J. Nutr. Sci. Vitaminol. 2015, 61, 375-381. [CrossRef] [PubMed]

13. Dong, Y.; Zhao, M.; Zhao, T.; Feng, M.; Chen, H.; Zhuang, M.; Lin, L. Bioactive profiles, antioxidant activities, nitrite scavenging capacities and protective effects on $\mathrm{H}_{2} \mathrm{O}_{2}$-injured PC12 cells of Glycyrrhiza. glabra L. leaf and root extracts. Molecules 2014, 19, 9101-9113. [CrossRef] [PubMed]

14. Vaya, J.; Belinky, P.A.; Aviram, M. Antioxidant constituents from licorice roots: Isolation, structure elucidation and antioxidative capacity toward LDL oxidation. Free Radic. Biol. Med. 1997, 23, 302-313. [CrossRef]

15. Zheng, Y.F.; Wei, J.H.; Fang, S.Q.; Tang, Y.P.; Cheng, H.B.; Wang, T.L.; Li, C.Y.; Peng, G.P. Hepatoprotective triterpene saponins from the roots of Glycyrrhiza. inflata. Molecules 2015, 20, 6273-6283. [CrossRef] [PubMed]

16. Sil, R.; Ray, D.; Chakraborti, A.S. Glycyrrhizin ameliorates metabolic syndrome-induced liver damage in experimental rat model. Mol. Cell. Biochem. 2015, 409, 177-189. [CrossRef] [PubMed]

17. Chen, M.; Christensen, S.B.; Blom, J.; Lemmich, E.; Nadelmann, L.; Fich, K.; Theander, T.G.; Kharazmi, A. Licochalcone A, a novel antiparasitic agent with potent activity against human pathogenic protozoan species of Leishmania. Antimicrob. Agents Chemother. 1993, 37, 2550-2556. [CrossRef] [PubMed] 
18. Gupta, V.K.; Fatima, A.; Faridi, U.; Negi, A.S.; Shanker, K.; Kumar, J.K.; Rahuja, N.; Luqman, S.; Sisodia, B.S.; Saikia, D.; et al. Antimicrobial potential of Glycyrrhiza. glabra roots. J. Ethnopharmacol. 2008, 116, 377-380. [CrossRef] [PubMed]

19. Fatima, A.; Gupta, V.K.; Luqman, S.; Negi, A.S.; Kumar, J.K.; Shanker, K.; Saikia, D.; Srivastava, S.; Darokar, M.P.; Khanuja, S.P.S. Antifungal activity of Glycyrrhiza. glabra extracts and its active constituent glabridin. Phytother. Res. 2009, 23, 1190-1193. [CrossRef] [PubMed]

20. Asha, M.K.; Debraj, D.; Prashanth, D.S.; Edwin, J.R.; Srikanth, H.S.; Muruganantham, N.; Dethe, S.M.; Anirban, B.; Jaya, B.; Deepak, M.; et al. In vitro anti-Helicobacter pylori activity of a flavonoid rich extract of Glycyrrhiza glabra and its probable mechanisms of action. J. Ethnopharmacol. 2013, 145, 581-586. [CrossRef] [PubMed]

21. Cheema, H.S.; Prakash, O.; Pal, A.; Khan, F.; Bawankule, D.U.; Darokar, M.P. Glabridin induces oxidative stress mediated apoptosis like cell death of malaria parasite Plasmodium falciparum. Parasitol. Int. 2014, 63, 349-358. [CrossRef] [PubMed]

22. Chakotiya, A.S.; Tanwar, A.; Narula, A.; Sharma, R.K. Alternative to antibiotics against Pseudomonas aeruginosa: Effects of Glycyrrhiza. glabra on membrane permeability and inhibition of efflux activity and biofilm formation in Pseudomonas aeruginosa and its in vitro time-kill activity. Microb. Pathog. 2016, 98, 98-105. [CrossRef] [PubMed]

23. Smolarczyk, R.; Cichoń, T.; Matuszczak, S.; Mitrus, I.; Lesiak, M.; Kobusińska, M.; Kamysz, W.; Jarosz, M.; Sieron, A.; Szala, S. The role of glycyrrhizin, an inhibitor of HMGB1 protein, in anticancer therapy. Arch. Immunol. Ther. Exp. 2012, 60, 391-399. [CrossRef] [PubMed]

24. Kwon, S.J.; Park, S.Y.; Kwon, G.T.; Lee, K.W.; Kang, Y.H.; Choi, M.S.; Yun, J.W.; Jeon, J.H.; Jun, J.G.; Park, J.H.Y. Licochalcone E present in licorice suppresses lung metastasis in the 4T1 mammary orthotopic cancer model. Cancer Prev. Res. 2013, 6, 603-613. [CrossRef] [PubMed]

25. He, S.Q.; Gao, M.; Fu, Y.F.; Zhang, Y.N. Glycyrrhizic acid inhibits leukemia cell growth and migration via blocking AKT/mTOR/STAT3 signaling. Int. J. Clin. Exp. Pathol. 2015, 8, 5175-5181. [PubMed]

26. Kamei, J.; Nakamura, R.; Ichiki, H.; Kubo, M. Antitussive principles of Glycyrrhizae radix, a main component of the Kampo preparations Bakumondo-to (Mai-men-dong-tang). Eur. J. Pharmacol. 2003, 469, 159-163. [CrossRef]

27. Ram, A.; Mabalirajan, U.; Das, M.; Bhattacharya, I.; Dinda, A.K.; Gangal, S.V.; Ghosh, B. Glycyrrhizin alleviates experimental allergic asthma in mice. Int. Immunopharmacol. 2006, 6, 1468-1477. [CrossRef] [PubMed]

28. Shin, Y.W.; Bae, E.A.; Lee, B.; Seung, H.L.; Jeong, A.K.; Kim, Y.S.; Kim, D.H. In vitro and in vivo antiallergic effects of Glycyrrhiza glabra and its components. Planta Med 2007, 73, 257-261. [CrossRef] [PubMed]

29. Qiao, X.; Ji, S.; Yu, S.W.; Lin, X.H.; Jin, H.W.; Duan, Y.K.; Zhang, L.R.; Guo, D.A.; Ye, M. Identification of key licorice constituents which interact with cytochrome P450: Evaluation by LC/MS/MS cocktail assay and metabolic profiling. AAPS J. 2014, 16, 101-113. [CrossRef] [PubMed]

30. Artursson, P.; Karlsson, J. Correlation between oral drug absorption in humans and apparent drug permeability coefficients in human intestinal epithelial (Caco-2) cells. Biochem. Biophys. Res. Commun. 1991, 175, 880-885. [CrossRef]

31. Yee, S. In vitro permeability across Caco-2 cells (colonic) can predict in vivo (small intestinal) absorption in man-fact or myth. Pharm. Res. 1997, 14, 763-766. [CrossRef] [PubMed]

32. Yang, X.W.; Yang, X.D.; Wang, Y.; Ma, L.; Zhang, Y.; Yang, X.G.; Wang, K. Establishment of Caco-2 cell monolayer model and standard operation procedure for assessing intestinal absorption of chemical components of traditional Chinese medicine. J. Chin. Integr. Med. 2007, 5, 634-641. [CrossRef]

33. U.S. Department of Health and Human Services, Food and Drug Administration, Center for Drug Evaluation and Research (CDER), Center for Veterinary Medicine (CVM). Guidance for Industry, Bioanalytical Method Validation. Available online: http://www.fda.gov/ucm/groups/fdagov-public/@fdagov-drugs-gen/ documents/document/ucm368107.pdf. (accessed on 27 September 2017).

34. Yang, X.W. Absorption, Distribution, Metabolism, Excretion, Toxicity and Activity in Traditional Chinese Medicines, 1st ed.; China Medical Science and Technology Press: Beijing, China, 2006; pp. 1075-1104. ISBN 7-5067-3337-4.

35. Tian, X.J.; Yang, X.W.; Yang, X.D.; Wang, K. Studies of intestinal permeability of 36 flavonoids using Caco-2 cell monolayer model. Int. J. Pharm. 2009, 367, 58-64. [CrossRef] [PubMed] 
36. Zhang, L.Q.; Huang, Y.D.; Yang, X.W. Intestinal permeability of liquiritin and isoliquiritin in the Caco-2 cell monolayer model. J. Chin. Pharm. Sci. 2010, 19, 451-458. [CrossRef]

37. Chan, O.H.; Stewart, B.H. Physicochemical and drug-delivery considerations for oral drug bioavailability. Drug Discov. Today 1996, 1, 461-473. [CrossRef]

38. Wu, X.W.; Wei, W.; Yang, X.W.; Zhang, Y.B.; Xu, W.; Yang, Y.F.; Zhong, G.Y.; Liu, H.N.; Yang, S.L. Anti-inflammatory phenolic acid esters from the roots and rhizomes of Notopterygium. incisium and their permeability in the human Caco-2 monolayer cell model. Molecules 2017, 22, 935. [CrossRef] [PubMed]

39. Yang, X.W. Discovery strategy for effective and active constituents of Chinese material medica based on the processes of metabolism and disposition in intra-body. China J. Chin. Mater. Med. 2007, 32, 365-370.

40. Yang, X.W. Substance basis research on Chinese materia medica is one of key scientific problems of inheriting, development and innovation of Chinese materia medica. China J. Chin. Mater. Med. 2015, 40, 3429-3434.

Sample Availability: Samples of the compounds 1-10 are not available from the authors.

(C) 2017 by the authors. Licensee MDPI, Basel, Switzerland. This article is an open access article distributed under the terms and conditions of the Creative Commons Attribution (CC BY) license (http://creativecommons.org/licenses/by/4.0/). 